\title{
Validation of FOAM near-surface ocean current forecasts using Lagrangian drifting buoys
}

\author{
E. W. Blockley, M. J. Martin, and P. Hyder \\ Met Office, FitzRoy Road, Exeter, EX13PB, UK \\ Correspondence to: E. W. Blockley (ed.blockley@ metoffice.gov.uk) \\ Received: 10 February 2012 - Published in Ocean Sci. Discuss.: 17 April 2012 \\ Revised: 28 June 2012 - Accepted: 3 July 2012 - Published: 30 July 2012
}

\begin{abstract}
In this study, the quality of near-surface current forecasts from the FOAM ocean forecasting system is assessed using the trajectories of Lagrangian drifting buoys. A method is presented for deriving pseudo-Eulerian estimates of ocean currents from the positions of Surface Velocity Program drifters and the resulting data are compared to velocities observed by the global tropical moored buoy array. A quantitative analysis of the global FOAM velocities is performed for the period 2007 and 2008 using currents derived from over 3000 unique drifters (providing an average of 650 velocity observations per day). A potential bias is identified in the Southern Ocean which appears to be caused by wind-slip in the drifter dataset as a result of drogue loss. The drifter-derived currents are also used to show how the data assimilation scheme and a recent system upgrade impact upon the quality of FOAM current forecasts.
\end{abstract}

\section{Introduction}

Accurate predictions of currents in the ocean surface layer are important for many applications including off-shore commercial activities, military operations, renewable energy, safety at sea and shipping (e.g. Jacobs et al., 2009; Huckerby, 2011; Davidson et al., 2009). Additionally, transports in the mixed layer play a key role for many environmental issues, such as marine ecosystem monitoring and the tracking of oil spills and pollutants (e.g. Roberts, 1997; Brushett et al., 2011; King et al., 2011). In the field of operational oceanography there has been much work undertaken to assess the performance of model-derived tracer fields such as temperature or salinity in assimilative ocean models (Storkey et al., 2010; Hernandez et al., 2009; Dombrowsky et al., 2009). How- ever, owing to the fact that current observations are much less abundant, studies involving direct model-observation velocity comparisons are less common. Instead, surface currents are often compared with gridded velocity products inferred from a mixture of satellite altimetry and surface wind observations using geostrophic approximations and an Ekman balance approach (Hernandez et al., 2009; Dohan and Maximenko, 2010). Some examples of gridded products derived using these methods are Ocean Surface Current Analyses Realtime (OSCAR; Bonjean and Lagerloef, 2002), SURCOUF (Larnicol et al., 2006) and the Centre de Topographie des Océans et de l'Hydrosphère (CTOH; Sudre and Morrow, 2008).

Previously called the Surface Velocity Program (SVP), the Global Drifter Program has been using drifting buoys to measure near-surface velocities since 1979 (Lumpkin and Pazos, 2007). The positions of these drifting buoys, still known as SVP drifters, have previously been used to augment satellite gridded products (see, for example, the SCUD dataset of Maximenko and Hafner, 2010, as well as Maximenko et al., 2009; Rio et al., 2007). Additionally, time series of buoy positions have, after appropriate filtering and processing, been used for comparisons with gridded modelled currents (Lumpkin and Garzoli, 2005; Lumpkin and Garraffo, 2005). Drifting buoys can also be used to validate Lagrangian currents and model transports. Brushett et al. (2011) use drifting buoys alongside a numerical trajectory model to investigate the accuracy of modelled currents from various systems (including the FOAM system used in this study) with application to tracking oil spills. Meanwhile, Davidson et al. (2009) describe how Lagrangian currents can be used in search and rescue systems. 
The goal of this paper is to introduce a simple technique for validating near-surface model currents using pseudoEulerian observations derived from the positions of SVP drifters as briefly described by Martin (2011). In order to validate the process of producing currents from drifter positions, summary statistics from the drifter-derived current analysis are compared to statistics obtained from comparisons made against the global tropical moored buoy array (as introduced by Hyder et al., 2011). The drifter-current technique is then used to assess daily-mean global velocity fields from the Met Office FOAM system by directly comparing simulated currents with the pseudo-Eulerian observations.

This paper is structured as follows. In Sect. 2 we introduce the SVP drifters, the global tropical moored buoy array and the Met Office Forecast Ocean Assimilation Model (FOAM) system. In Sect. 3 we describe how we use the positions of the SVP drifters to derive daily-mean surface current observations. In Sect. 4 statistics from a drifter-derived current assessment in the tropics are compared with an analysis using currents observed by the global tropical moored buoy array. In Sect. 5 the drifter-derived currents are compared to simulated daily-mean currents from the global FOAM system for the period 2007-2008 and statistics are compared to an analysis performed using climatology fields. In Sect. 6 we extend the global FOAM assessment by analysing the currents from two additional FOAM experiments in order to investigate the respective impacts that the data assimilation and a recent FOAM upgrade have on the quality of the currents. The paper ends with a summary in Sect. 7.

\section{Description of data used in the study}

\subsection{The SVP drifting buoys}

The SVP drifters consist of a spherical surface buoy attached via a tether to a submerged "holey sock" drogue. The surface buoy contains all the electrical equipment such as a temperature sensor, battery and antenna as well as a tetherstrain gauge (or submergence sensor) to monitor the status of the drogue. The drogue is roughly $5 \mathrm{~m}$ long, centred at approximately $15 \mathrm{~m}$ depth and has a cross-sectional area approximately 40 times that of the tether and the surface buoy. This 40:1 drag area ratio means that the SVP drifter will follow the $15 \mathrm{~m}$ currents with a wind slip of less than $0.1 \%$ of the wind speed for winds of strength up to $10 \mathrm{~m} \mathrm{~s}^{-1}$ (Niiler et al., 1995 calculated a slip of less than $1 \mathrm{~cm} \mathrm{~s}^{-1}$ for the global average wind speed of $8 \mathrm{~m} \mathrm{~s}^{-1}$, although no tests were carried out in winds greater than $10 \mathrm{~m} \mathrm{~s}^{-1}$ ). If the drogue should become detached, the surface buoy will be subject to increased wind slip as well as other effects such as Stokes drift and shear effects from wind-driven surface currents. All of these factors increase the downwind slippage for an undrogued buoy to approximately $1 \%$ of the wind speed; Poulain et al. (2009), based on experiments carried out in the in the Eastern Mediterranean, calculated a minimum of $7 \mathrm{~cm} \mathrm{~s}^{-1}$ slip in $10 \mathrm{~m} \mathrm{~s}^{-1}$ winds for SVP drifters. Most SVP drifters are tracked by the Argos Data Collection and location system on the NOAA polar-orbiting satellites, and the reported locations are accurate to approximately $1 \mathrm{~km}$. Drifter data can be obtained in near-real-time through the Global Telecommunication System (GTS) or as qualitycontrolled delayed-mode data from the Global Drifter Program (GDP) available via download from http://www.aoml. noaa.gov/phod/dac/dacdata.php. These delayed-mode GDP data are quality-controlled to remove undrogued and shipboard drifters and include 6-hourly velocity estimates as well as error bars for their positions. The GTS data meanwhile do not include velocity estimates (only positional information and surface measurements of SST) and are not subject to the velocity-specific quality control procedures that are applied to the GDP data.

In this study, despite the obvious advantages to using the quality-controlled GDP dataset, we shall infer near-surface ocean currents from the near-real-time GTS drifter data. The reason for using the GTS data is that we wish to implement this ocean current verification into the FOAM system of Storkey et al. (2010) in near-real-time.

\subsection{The global tropical moored buoy array}

The global tropical moored buoy array is a multi-national effort to provide tropical met-ocean data in real-time for forecasting and climate research. The main purpose of the moored buoy array is to monitor interannual climate fluctuations in the tropics (e.g. El Niño Southern Oscillation (ENSO), Madden-Julian Oscillation (MJO)), the Pacific and Indian Ocean monsoons as well as hurricane (typhoon) activity in the Atlantic (Pacific) Ocean. Major components include the TAO/TRITON array in the Pacific Ocean, PIRATA in the Atlantic Ocean, and RAMA in the Indian Ocean (Hayes et al., 1991; Servain et al., 1998; McPhaden et al., 2009). In addition to observing temperature, salinity and various atmospheric quantities, many of these moorings now carry current meters, which provide velocity observations accurate to within $5 \mathrm{~cm} \mathrm{~s}^{-1}$, at a range of depths including $10 \mathrm{~m}$. These data are independent and have not been assimilated into the FOAM system - although the corresponding temperature and salinity measurements have been. The moored buoy array, therefore, provides a useful independent velocity dataset at $10 \mathrm{~m}$ depth albeit with limited latitudinal extent. Observations from the global tropical moored buoy array can be obtained from the TAO Project Office of NOAA/PMEL via download from http://www.pmel.noaa. gov/tao/data_deliv/deliv.html.

\subsection{The FOAM system}

The Forecast Ocean Assimilation Model (FOAM) system is an operational ocean forecasting system run daily at the 
Met Office which produces an analysis and 7-day forecast of ocean currents and tracers (Storkey et al., 2010). The system consists of a $1 / 4^{\circ}$ resolution global configuration with three nested $1 / 12^{\circ}$ regional configurations in the North Atlantic, Indian Ocean and Mediterranean Sea basins. The hydrodynamic model component of FOAM is the NEMO primitive equation ocean model (Madec, 2008) coupled to the LIM2 sea-ice model (Timmermann et al., 2005). Data assimilation is performed using an analysis correction first guess at appropriate time (FGAT) scheme (Martin et al., 2007) with the following types of data being assimilated: sea level anomaly (SLA), sea surface temperature (SST), profiles of temperature and salinity as well as sea-ice concentration. The global FOAM configuration runs as part of the FOAM system and provided backup global products during the first MyOcean project (http://www.myocean.eu/). The configuration is based on the tri-polar configuration of Drévillon et al. (2008) with $1 / 4^{\circ}(28 \mathrm{~km})$ grid spacing near the Equator reducing to $6 \mathrm{~km}$ at high latitudes. More information on the FOAM setup and an initial validation of tracer fields can be found in the system description of Storkey et al. (2010).

In autumn 2010, several upgrades were applied to the operational FOAM system as described by Storkey et al. (2010), primarily to the assimilation system. As part of this upgrade, the mean dynamic topography (MDT) used for the SLA assimilation was updated from the Rio et al. (2007) dataset to the new CNES09 MDT of Rio et al. (2011). The assimilation system error co-variances were replaced with newly calculated and seasonally varying estimates. The NEMO model component was upgraded from NEMO vn3.0 to vn3.2 which included a change to the TKE vertical mixing scheme to make it energetically consistent (Burchard, 2002). The horizontal momentum diffusion scheme was changed from using a Laplacian only scheme to a mixed Laplacian/biharmonic scheme. Additionally, an error was fixed in the observation processing that was causing some of the SLA data to not be assimilated in the offline FOAM hindcast experiments (but not the operational system). More detailed information on this upgrade can be found in Storkey (2011).

As the version of the FOAM system reported by Storkey et al. (2010) was implemented for MyOcean V0, we call this "FOAM V0", and, as the upgrades listed above were operational in time for MyOcean V1, we term the updated system "FOAM V1". The analysis performed in this study primarily involves the assessment of the FOAM V1 system which, at the time of writing, is running operationally at the Met Office. Therefore, any reference to FOAM data used will be from the FOAM V1 system unless otherwise stated.

\section{Deriving near-surface currents from drifter positions}

Using the reported positions of SVP drifters, we derive pseudo-Eulerian daily-mean currents in a simple fashion. We do this by using the first and last reports of each day to de- termine the distance travelled during the course of the day (both in latitude and longitude) and the time taken to do so - from which we derive the velocity. We assume that each derived velocity observation is valid at midday and located at the mid-point between the first and last reporting position of the day.

Before deriving currents, drifters whose temperature observations failed the SST quality control process (Storkey et al., 2010; Ingleby and Lorenc, 1993) are removed, as this failure could be indicative of poor/inaccurate location reporting. The derived velocities are then quality controlled with the following cases being removed from the observation set: drifters known to have lost their drogue, velocities greater than $3.5 \mathrm{~m} \mathrm{~s}^{-1}$ and velocities whose reporting length for that day is less than $8 \mathrm{~h}$. The relatively high maximum velocity threshold of $3.5 \mathrm{~m} \mathrm{~s}^{-1}$ has been chosen to remove any spurious currents derived from drifters attached to (or onboard of) ships without blacklisting velocities in western boundary currents.

The benefits of this method are that it is simple to implement and provides quite a large number of current observations (in excess of 600 per day globally). Additionally, and provided the time window is long enough, considering the total distance travelled during a day means that the impact of tidal currents is lessened. Likewise, the effect of inertial currents will be reduced although not removed completely. These current observations are an almost independent dataset, as the currents have not been assimilated into the system. However, they are not completely independent because the drifter positions contribute towards the calculation of the MDT (along with geostrophic and Ekman currents) used in the SLA assimilation. This dependence on the MDT would only be expected to have an effect on the largescale, long-term circulation of the model meaning that the drifter observations can be effectively considered independent for current variations about the long-term mean.

Figure 1 shows a typical daily distribution of drifterderived pseudo-Eulerian zonal velocity observations taken from the beginning of January 2007 as well as the average number of observations per day, in $2^{\circ}$ bins, for the period 2007-2008. It is clear from Fig. 1b that there is not an even spread of drifter observations with much higher concentrations in the North Atlantic and Japan Sea amongst other areas. This non-uniform distribution of drifters is, in part, owing to the buoy release locations which tend to be concentrated in areas of interest such as the Gulf of Mexico or Drake Passage, or in areas of high shipping such as the North Atlantic and the western North Pacific.

Owing to the simplicity of the averaging used in the creation of these pseudo-Eulerian observations, there are a few key points to note before the data are used for validating model current fields. As the velocities are derived directly from straight line horizontal displacements each day, they underestimate the speed of the drifter in situations where the buoy trajectory has a significant curvature (an effect that will 
U: mean obs: $2007 / 01 / 01$ to $2007 / 01 / 01$

Points: 735 depths: $0-0$ extrema: $-2.449,1.126$ mean: -0.009903 rms: 0.2901

(a)

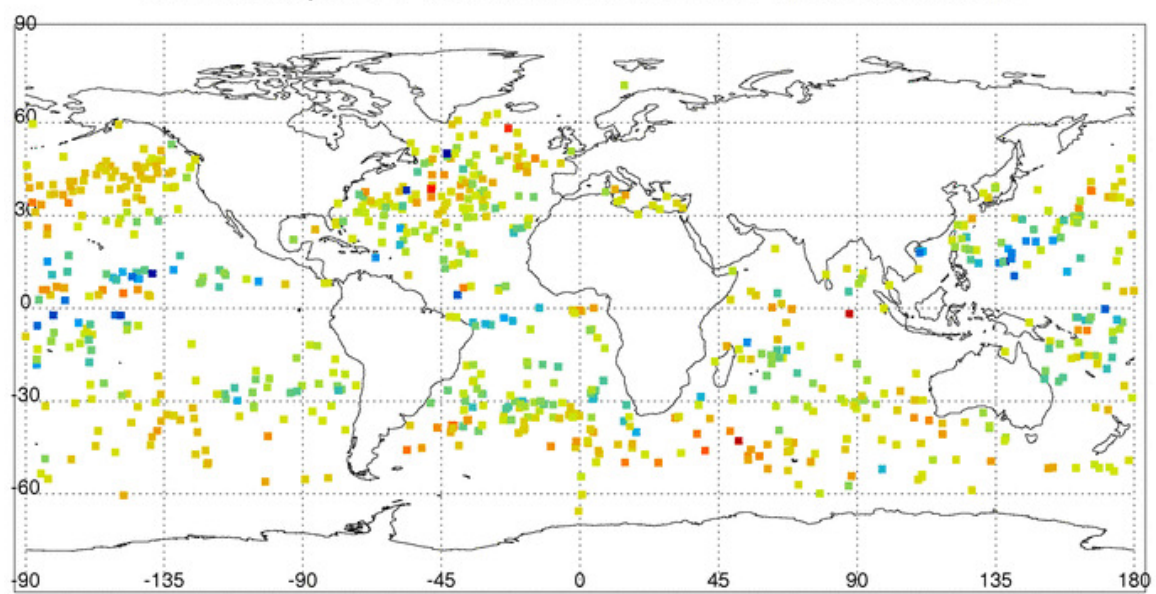

(b)

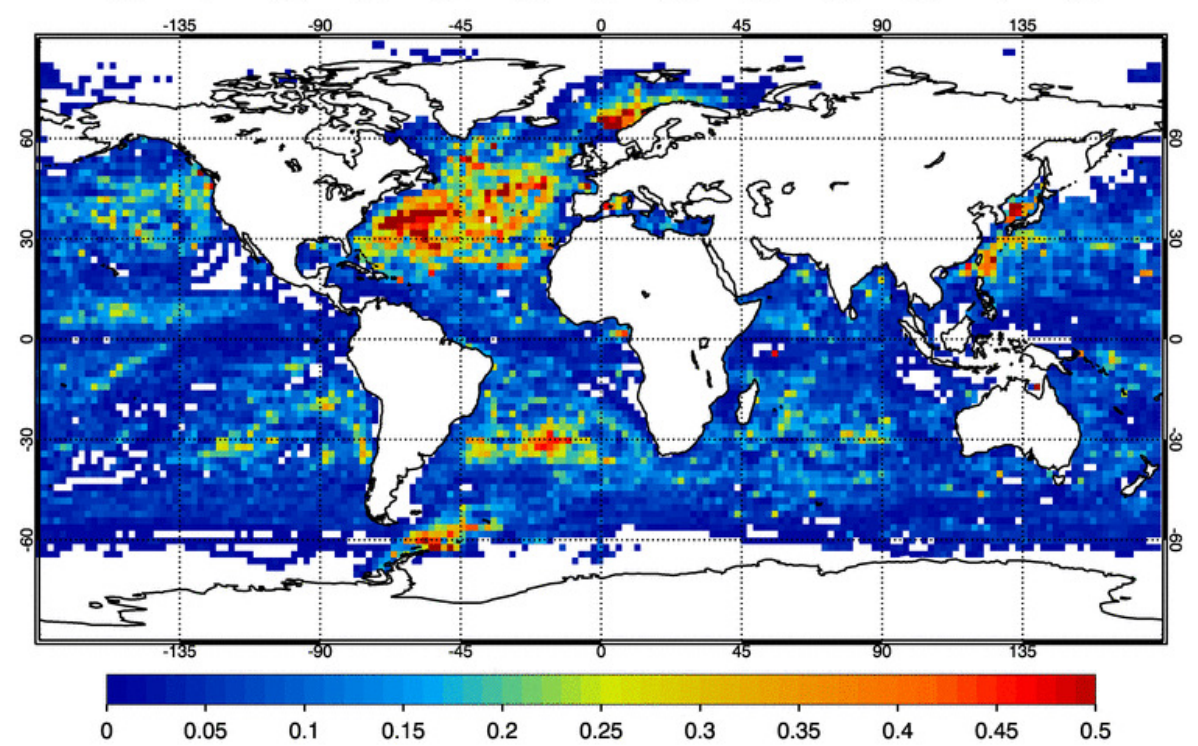

Fig. 1. The distribution of drifter-derived currents: (a) a typical daily distribution of velocity observations taken from 1 January 2007 , (b) the average number of observations per day for the 2-yr period 2007-2008 in $2^{\circ}$ bins.

be more pronounced in high latitudes where the Rossby radius of deformation is lower). Therefore, the drifter-derived pseudo-Eulerian velocity observations are an underestimate of the true daily-mean $15 \mathrm{~m}$ currents (albeit only slightly). Additionally, with a model grid spacing of at most $28 \mathrm{~km}$, any derived velocity above $0.3 \mathrm{~m} \mathrm{~s}^{-1}$ will almost certainly be constructed using reports from positions spanning multiple grid cells; we therefore perform horizontal interpolation when co-locating modelled and observed values. Moreover, as the reported locations of the buoys are only accurate to approximately $1 \mathrm{~km}$, we must be wary of drifters that have not travelled very far during the reporting period and whose location error could be much higher, relatively, than buoys that have travelled further.
Pseudo-Eulerian $15 \mathrm{~m}$ velocities were derived for the period 2007-2008 from over 3000 unique drifters using data obtained from the GTS. After implementing the quality control measures outlined above, using drogue status information obtained from the GDP website, this resulted in an average of 653 good quality drifter observations per day. These drifter-derived velocities can be compared with modelled FOAM current fields by co-locating observations with dailymean model values. These observation-model co-locations, or match-ups, were performed using bilinear interpolation in the horizontal direction and by identifying the nearest model depth level to the observation depth in the vertical. As FOAM uses z-level depth coordinates, the nearest model level to the mean drogue depth of $15 \mathrm{~m}$ was $15.87 \mathrm{~m}$ for all observations. 
Table 1. Comparison of summary statistics for FOAM V1 velocity analyses against the global tropical moored buoy array (top half) and the drifter-derived currents (bottom half) for the whole of the global equatorial ocean. Statistics for zonal velocity are in Table 1a and for meridional velocity in Table 1b. Summary measures shown are mean error (observation-model), root-mean-square error (RMSE), Pearson correlation and the standard deviation of the observations. Also included are the average numbers of observations per day. Results are shown separately for two regions defined as being within $10^{\circ}$ and $2^{\circ}$ of the Equator respectively.

\begin{tabular}{lrrrrr}
\hline (a) Zonal: & mean & RMSE & correlation & obs s.d. & no. obs/day \\
\hline Moored Buoys: & & & & & \\
$10^{\circ} \mathrm{S}-10^{\circ} \mathrm{N}$ & 0.13 & 0.30 & 0.78 & 0.35 & 20 \\
$2^{\circ} \mathrm{S}-2^{\circ} \mathrm{N}$ & 0.22 & 0.37 & 0.77 & 0.42 & 11 \\
\hline Drifting Buoys: & & & & & \\
$10^{\circ} \mathrm{S}-10^{\circ} \mathrm{N}$ & -0.02 & 0.24 & 0.73 & 0.34 & 79 \\
$2^{\circ} \mathrm{S}-2^{\circ} \mathrm{N}$ & 0.04 & 0.33 & 0.72 & 0.45 & 11 \\
\hline (b) Meridional: & & & & & \\
\hline Moored Buoys: & & & & & \\
$10^{\circ} \mathrm{S}-10^{\circ} \mathrm{N}$ & -0.004 & 0.19 & 0.55 & 0.20 & 20 \\
$2^{\circ} \mathrm{S}-2^{\circ} \mathrm{N}$ & 0.006 & 0.20 & 0.56 & 0.22 & 11 \\
\hline Drifting Buoys: & & & & & \\
$10^{\circ} \mathrm{S}-10^{\circ} \mathrm{N}$ & -0.001 & 0.20 & 0.59 & 0.23 & 79 \\
$2^{\circ} \mathrm{S}-2^{\circ} \mathrm{N}$ & -0.003 & 0.23 & 0.54 & 0.26 & 11 \\
\hline
\end{tabular}

\section{Comparison of drifter-derived velocities with current moorings in the tropics}

Owing to the assumptions made whilst deriving our pseudoEulerian velocity observations, it is important to investigate the accuracy of the dataset before using it to validate the FOAM currents. To do this, we compare the data to independent velocities observed by the global tropical moored buoy array.

The most complete way to perform this comparison would be to directly compare the drifter-derived pseudo-Eulerian observations with the moored buoy observations. However, this is not feasible for this study because the number of legitimate drifter-mooring co-locations (i.e. where a drifter passes through the nearest grid cell to a mooring) would not provide enough data for a thorough analysis. Furthermore, the velocities observed by the two datasets are at different depths; the drifters are drogued at $15 \mathrm{~m}$ and the moorings observe at $10 \mathrm{~m}$. As a result of these factors, we would expect the model errors to be more clearly related than the observed currents in this situation (i.e. we expect the model errors to be more consistent between the two depths than the actual measured currents). Therefore, we compare both datasets against the modelled FOAM currents and analyse the resulting differences.

To perform these comparisons, daily-mean velocity vectors observed by the global tropical moored buoy array were compared with FOAM currents by matching each observation with an interpolated modelled value in the same manner used for the drifter-derived currents (i.e. using bilinear interpolation in the horizontal and the nearest model depth level in the vertical). The nearest model level to the $10 \mathrm{~m}$ observation depth is $9.57 \mathrm{~m}$. Using these match-ups, we calculate the mean error (observed-modelled values), root-meansquare (RMS) error and Pearson correlation coefficient averaged in both space and time. As well as calculating statistics for the equatorial band between $10^{\circ} \mathrm{S}$ and $10^{\circ} \mathrm{N}$, we also report statistics separately between $2^{\circ} \mathrm{S}$ and $2^{\circ} \mathrm{N}$ where most of the tropical buoys are moored. These summary statistics can be found in the top halves of Table $1 \mathrm{a}$ and $\mathrm{b}$ for zonal and meridional velocities, respectively. Also calculated are the standard deviations of the observed values, which we include as a measure of the variability of the observations. The corresponding statistics for the drifter-derived current comparisons can be found in the lower halves of Table 1a and $b$ respectively.

Correlations and RMS errors are of similar magnitude for both the moored buoy and the drifting buoy analysis for both zonal and meridional currents. For zonal current, the validation against drifters has slightly lower RMS errors but also lower correlations, whilst for the meridional currents the opposite is true with higher RMS errors and higher correlations. The standard deviations of the drifter-derived and moored buoy observations are also similar, although there does appear to be a little more variability in the drifter-derived currents - particularly for the meridional currents.

The values of the mean errors are quite different between $10^{\circ} \mathrm{S}$ and $10^{\circ} \mathrm{N}$, with the drifter analysis having much smaller mean errors than the moored buoy analysis. However, this regional average bias is not a very useful summary measure for velocity fields and provides little information about the errors in the model or the differences between the 
(a)

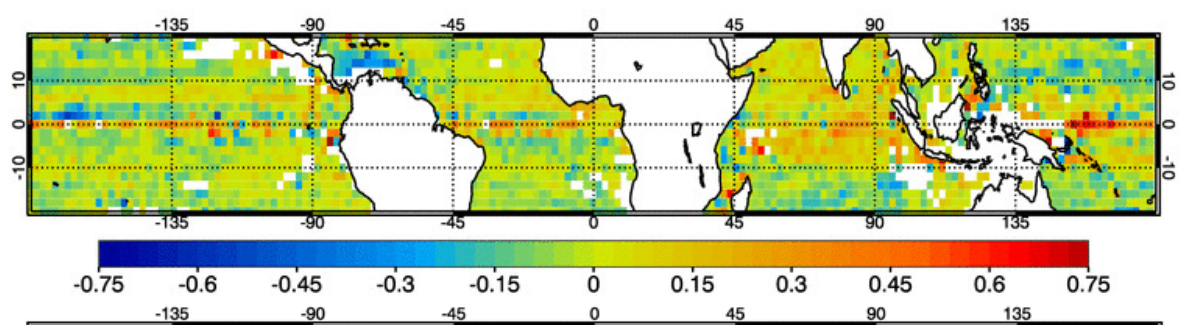

(b)

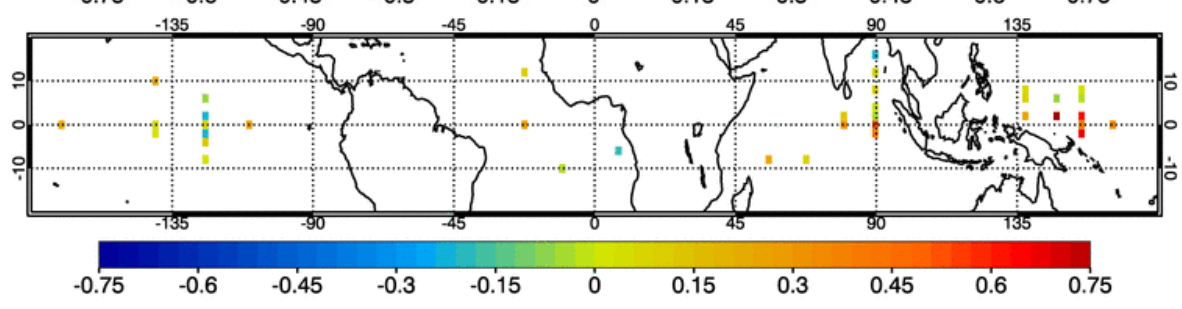

Fig. 2. Zonal velocity errors (observed-modelled), in $2^{\circ}$ bins, over the range $20^{\circ} \mathrm{S}$ to $20^{\circ} \mathrm{N}$ for (a) the drifter-derived current validation and (b) the moored buoy validation.

two sets of observations. This is because velocities are unilateral and can be either positive or negative depending on the direction of travel. With current fields being high in horizontal shear, the regional average bias will be composed of errors in different regimes which can potentially conflict and cancel each other out. This is particularly true in the tropics where there are a number of strong currents travelling in opposite directions (e.g. North Equatorial Current, South Equatorial Current and Equatorial Counter Current). Moreover, for this comparison the different spatial distributions of the observations compound the problem because the drifter-derived observations cover most of the region, whilst the moored buoys only sample a relatively small part of it being biased towards the equatorial locations.

However, it is interesting that the regional mean errors suggest the same pattern in both sets of observations, whereby there is a much stronger westward bias within $2^{\circ}$ of the Equator than within $10^{\circ}$. This point is illustrated in Fig. 2 which shows spatial maps of the time-mean observed-modelled velocities for both the drifter-derived currents and the moored buoy currents. This westward bias along the Equator is thought to be related to errors in the surface wind fields coupled with an underestimation of the wind-induced vertical mixing in the tropics.

Results from a short test run performed using relative wind stresses, rather than absolute wind stresses, (Deng et al., 2009) show a much reduced bias at the Equator (C. Guiavarc'h, personal communication, 2011). However, evidence suggests that the use of relative wind stresses can lead to a smoothing of the surface currents within mesoscale features particularly outside the tropics where the Rossby radius is lower (B. Barnier, personal communication, 2012; Eden and Dietze, 2009). Further investigation therefore will be required to better understand the cause of this bias before this issue can be resolved. Additional discussion of this westward equatorial bias can be found in Hyder et al. (2011).
The regional averaged moored buoy statistics are skewed by the large number of moorings based along the Equator where the model is biased towards the west. Table 1 shows that more than half (55\%) of the moored buoy observations are contained within $2^{\circ}$ of the Equator, whilst the corresponding figure for drifter observations is approximately $14 \%$. Whilst there are just as many drifter observations as moored buoy observations within $2^{\circ}$ of the Equator, these tend to be distributed evenly across the region, whereas most of the moored buoys are located on the Equator itself. Additionally, the number of drifter observations continues to increase with increasing distance from the Equator so that there are almost four times as many drifter-derived observations within $10^{\circ}$ of latitude than moored buoy observations. It is this difference in the spatial distribution of the observations that is responsible for most of the differences in the regional mean biases. Meanwhile, the plots in Fig. 2 show good agreement between the spatial distribution of mean errors for the moored buoys and the drifter-derived currents - in particular in the western tropical Pacific and the Indian Ocean.

These results give us confidence in the pseudo-Eulerian drifter observations and, more specifically, in the drifterderived validation technique. We shall therefore apply the drifter analysis to areas of the ocean where other sources of regular velocity observations are scarce.

\section{Global drifter current analysis}

\subsection{Global FOAM comparisons}

In this section, we extend the drifter-derived current analysis to the global ocean and perform match-ups between the modelled FOAM daily-mean currents and the drifterderived current observations as described in previous sections. From these match-ups, we calculate mean error, RMS 
(a)

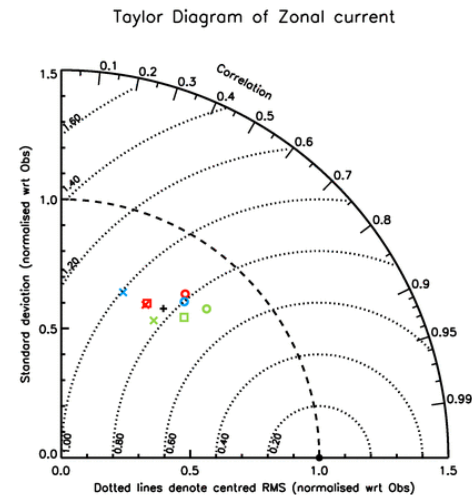

(b)

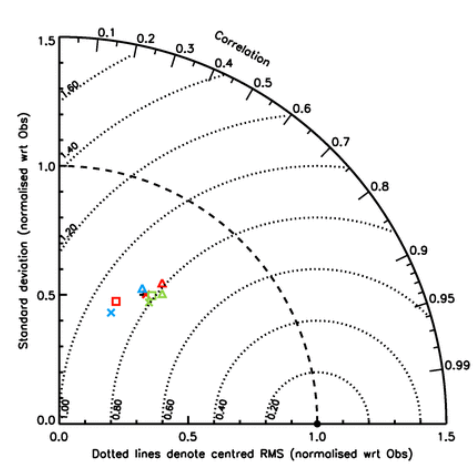

Taylor Diagram of Meridional current

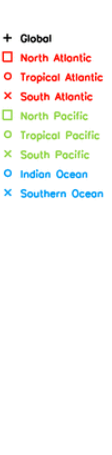

(c)

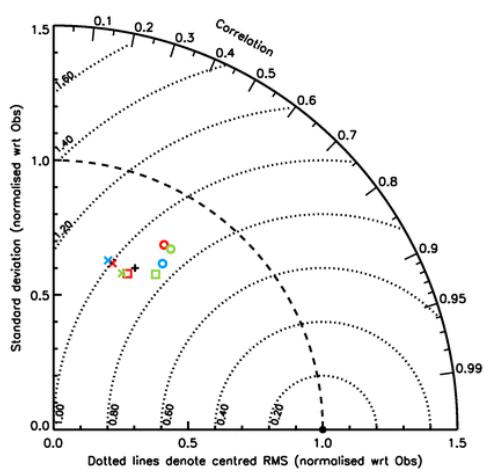

(d)

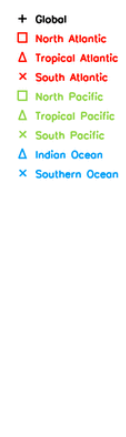

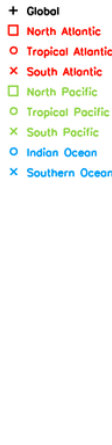
Taylor Diogram of Meridional current

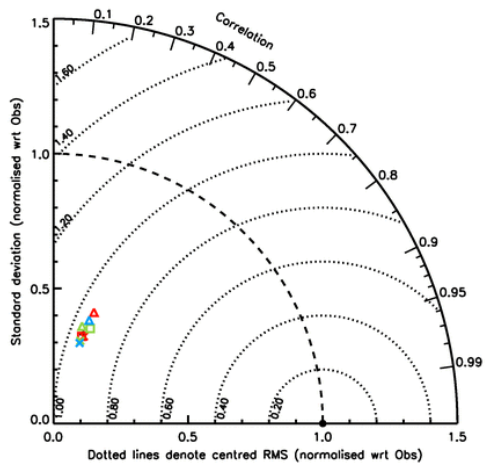

+ Globol

$\triangle$ Tropical Atlontic

$\times$ South Allontic

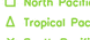

$x$ South Pocitic

Fig. 3. Taylor plots showing the global drifter current validation for the FOAM V1 hindcast run (a) and for the drifter climatology (b) for zonal velocity. Corresponding Taylor plots for meridional velocity can be found in (c) and (d). Results are shown for the whole global ocean as well as the same sub-basin areas used in Table 2 .

error, Pearson correlation and normalised standard deviation summary statistics. The mean error is included for completeness with the caveat that, owing to the issues described in the previous section, it should not be used for diagnosing systematic biases in the system except in areas of unidirectional or large-scale mean flow. The normalised standard deviation is calculated as the ratio of the model standard deviation to the observed standard deviation. It is used here as a measure of how well the model captures the observed variability of the ocean.

The results of this analysis can be found in Table 2 where summary statistics are given both for the global ocean and regions covering the main ocean basins. These results are also represented pictorially as Taylor plots in Fig. 3a and c for zonal and meridional velocities, respectively (see Taylor, 2001; Martin, 2011). The Mediterranean Sea and Arctic Ocean regions are not included in this list, because there were too few observations in these regions to give statistically significant results.

The results in Table 2 show that the RMS error is remarkably consistent between the various regions - although in general the Southern and Indian Oceans yield the highest errors, whilst the Pacific Ocean the lowest. The normalised standard deviations are all below unity which means that the model underestimates the variability of both the zonal and meridional currents in all regions. The most likely reason for this is that the combination of the horizontal resolution of the eddy-permitting model coupled with the 6-hourly wind fields used to force the surface boundary is too coarse to capture submesoscale, or even relatively fine-scale mesoscale, features. The variability is better in the tropics and the Indian Ocean where the model is accounting for about $80 \%$ of the observed variability.

The correlation coefficients suggest that FOAM zonal currents are more skilful than meridional currents with global correlations of 0.57 and 0.45 respectively. Correlations are higher in the tropics, the Indian Ocean and the North Pacific with zonal current correlations exceeding 0.6 in these regions - where a value of at least 0.6 is often taken as indicative of a useful forecast (Hollingworth et al., 1980; Murphy and Epstein, 1989). Meridional current correlations are also higher in these areas with values exceeding 0.5. In general, skill in the Pacific is better than in the Atlantic, which can be explained by the fact that dynamic, eddying regions make 
Table 2. Drifter-derived current validation of the FOAM V1 2007-2008 hindcast zonal velocities (a) and meridional velocities (b). Summary statistics shown include the mean error (observed-modelled), root-mean-square error (RMSE), Pearson correlation coefficients and normalised standard deviations (the ratio of standard deviation for the modelled and observed currents). Also shown are the average numbers of drifter-derived observations per day. Results are shown for the whole global ocean as well as various other regions.

\begin{tabular}{lrrrrr}
\hline (a) Zonal: & mean & RMSE & correlation & norm. s.d. & obs/day \\
\hline Global & -0.004 & 0.21 & 0.57 & 0.70 & 653 \\
North Atlantic & -0.003 & 0.21 & 0.49 & 0.68 & 179 \\
Tropical Atlantic & -0.004 & 0.21 & 0.60 & 0.80 & 40 \\
South Atlantic & 0.009 & 0.22 & 0.48 & 0.68 & 99 \\
North Pacific & -0.022 & 0.21 & 0.66 & 0.72 & 139 \\
Tropical Pacific & -0.051 & 0.21 & 0.70 & 0.81 & 91 \\
South Pacific & 0.000 & 0.20 & 0.56 & 0.64 & 135 \\
Indian Ocean & -0.021 & 0.23 & 0.62 & 0.77 & 79 \\
Southern Ocean & 0.064 & 0.24 & 0.35 & 0.68 & 130 \\
\hline (b) Meridional: & & & & & \\
\hline Global & 0.001 & 0.19 & 0.45 & 0.67 & 653 \\
North Atlantic & 0.002 & 0.19 & 0.43 & 0.64 & 179 \\
Tropical Atlantic & 0.006 & 0.16 & 0.51 & 0.80 & 40 \\
South Atlantic & -0.001 & 0.20 & 0.34 & 0.66 & 99 \\
North Pacific & -0.009 & 0.19 & 0.55 & 0.69 & 139 \\
Tropical Pacific & -0.004 & 0.17 & 0.55 & 0.80 & 91 \\
South Pacific & 0.006 & 0.17 & 0.40 & 0.63 & 135 \\
Indian Ocean & 0.013 & 0.21 & 0.55 & 0.74 & 79 \\
Southern Ocean & -0.007 & 0.22 & 0.31 & 0.66 & 130 \\
\hline
\end{tabular}

up a larger proportion of the Atlantic Ocean than the Pacific Ocean with more areas of high mesoscale activity; the Gulf Stream separation, the North Brazil Current and the Falklands Confluence present tough challenges to ocean models. The Southern Ocean meanwhile shows the lowest level of skill, and, with correlations of 0.35 and 0.31 for zonal and meridional current respectively, model skill in this area is poor which will be discussed further later on in this section.

\subsection{Comparisons with climatology}

In order to better understand the level of skill that the modelled currents have, we need to determine how well the model performs relative to using climatology-based predictions. In particular, the large-scale zonal flows of the tropical Pacific and the seasonal circulations of the Indian Ocean that gave the highest correlations (in Table 2) may be captured just as well by a velocity climatology. To test this, we obtained the Global Drifter Program's drifter-derived velocity climatology (Lumpkin and Garraffo, 2005) and, using the process outlined above, compared this with the drifter-derived currents by calculating match-ups for each observation. This comparison is a difficult one for the model, because the observations used to validate the model are also those used to develop the climatology. However, we would still expect the model to perform better than the climatology and, in particular, to better reproduce the variability of the observations.
The analysis performed above was repeated using these climatology fields in place of the FOAM modelled currents and the results plotted in Fig. $3 \mathrm{~b}$ and $\mathrm{d}$.

Comparison of the Taylor diagrams in Fig. $3 \mathrm{a}$ and $\mathrm{b}$ shows that for zonal currents the FOAM predictions are better than the climatology with generally lower RMS errors, higher correlations and normalised standard deviations closer to the ideal ratio of 1 . This can be seen by comparing the Taylor plots in Fig. 3a and b. The FOAM meridional currents also prove to be much better than climatology with slightly lower RMS errors and much higher correlations. The largest improvement over climatology is with the variability of the meridional currents, as the normalised standard deviations for FOAM are almost twice the size of those for the climatology (Fig. 3c and d). This means that FOAM is capturing almost twice as much of the meridional current variability as the climatology - which should be expected given that meridional flows are generally dominated by short-period features such as tropical instability waves and mesoscale eddies rather than large-scale mean flows. In particular, we note that the worst correlation for the meridional climatology comparisons is in the tropical Pacific region where the flow is influenced by tropical instability waves.

Interestingly, in contrast to the FOAM analysis, the correlations for the climatological analysis in the Southern Ocean are not considerably worse than for the other regions. The climatology zonal current fields actually give a higher correlation than the FOAM zonal currents, whilst the 
corresponding meridional correlations are of a comparable magnitude. These unexpected results are discussed further in Sect. 5.3 below.

\subsection{Southern Ocean currents}

In addition to the poor correlation coefficients in the Southern Ocean, there is also a mean error in the zonal currents of $6.4 \mathrm{~cm} \mathrm{~s}^{-1}$ to the west (see Table 2a) suggesting that the large-scale mean eastward flow in this region, the Antarctic Circumpolar Current (ACC), is consistently underestimated in the FOAM model. This can be clearly seen in Fig. 4a, which shows the mean zonal velocity errors (observed-modelled), in $2^{\circ}$ bins, for the whole assessment period 2007-2008.

However, the FOAM currents in this region (see Fig. 5a) appear to be realistic, and the frontal locations of the ACC (see Orsi et al., 1995; Falco and Zambianchi, 2011; Sokolov and Rintoul, 2009) are well defined. In contrast, this is not the case for the observed current field (Fig. 5b) which is characterised by widespread, relatively strong currents more consistent with the overlying wind field. The mean strength of the modelled ACC currents is approximately $0.2 \mathrm{~m} \mathrm{~s}^{-1}$ outside of the main frontal zones, in keeping with the findings of Falco and Zambianchi (2011) and Olbers et al. (2004), whereas, at almost $0.5 \mathrm{~m} \mathrm{~s}^{-1}$, the drifter-derived currents appear too strong in these areas. Furthermore, the averaged total transport through Drake Passage for the FOAM system run was approximately $173 \mathrm{~Sv}$. This value is higher than the estimated climatological upper bound of $146 \mathrm{~Sv}$ (Cunningham et al., 2003; Olbers et al., 2004; Whitworth and Peterson, 1985), which suggests that the FOAM currents are too strong in this region. This proposition is further supported by the fact that, throughout the FOAM run, the SLA assimilation was trying to weaken the ACC by reducing the surface pressure gradient across the sub-polar front (not shown here). Moreover, Maximenko et al. (2009) find this same problem whilst using the drifter dataset to derive mean dynamic topographies. When comparing magnitudes of mean drifter velocity against mean geostrophic plus Ekman velocity, the differences in the Southern Ocean were very pronounced (see their Fig. 2a and $\mathrm{b}$ respectively). They conclude that the method using the drifter velocities leads to an overestimated surface pressure gradient across the ACC. As a further comparison, we plot the corresponding 2007-2008 average zonal currents from the OSCAR dataset (Bonjean and Lagerloef, 2002) in Fig. 5c. The OSCAR Southern Ocean currents in Fig. 5c are much weaker than the drifter-derived currents in Fig. 5b, with maximum values around $0.5 \mathrm{~m} \mathrm{~s}^{-1}$, being closer to the magnitude of the FOAM currents rather than the $0.8 \mathrm{~m} \mathrm{~s}^{-1}$ of the drifter data. The structure of the OSCAR currents is also more aligned with the FOAM currents, being composed of occasional frontal zones rather than strongly eastward zonal flows.
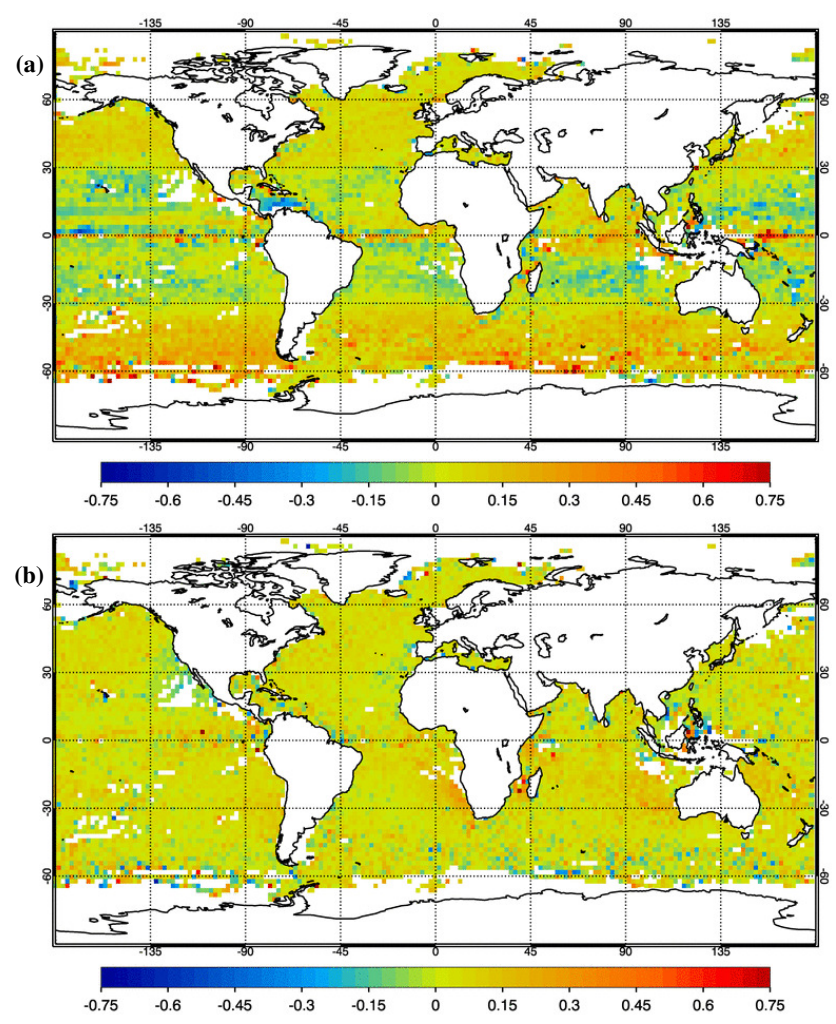

Fig. 4. Mean error (observed-modelled) against drifters for (a) zonal velocity and (b) meridional velocity in $2^{\circ}$ bins.

We therefore suspect that part of the mismatch between modelled and observed velocities is due to a bias in the drifter dataset. If this were the case, then the drifter climatology would have the same bias which would explain the higher correlations for the climatological velocity comparisons earlier in this section. The most likely reason for a bias would be slippage of the drifters and associated Stokes drift arising from the strong westerly winds over the Southern Ocean. Winds in this region can be very strong indeed - in excess of $40 \mathrm{~m} \mathrm{~s}^{-1}$ - and certainly exceed the $10 \mathrm{~m} \mathrm{~s}^{-1}$ maximum value used to derive the windage figure of $0.1 \%$ (Niiler et al., 1995; Poulain et al., 2009). It is feasible that wind-slip in the Southern Ocean may not fit this linear relationship (which was derived in much calmer conditions) and that drifters in the ACC are moving even faster relative to the ocean currents they are designed to follow.

Another consideration is that the drifter dataset may well contain a number of buoys with missing drogues that have not been correctly identified as being undrogued. These drifters would be considerably more susceptible to the effects of the Southern Ocean winds and could skew the drifter dataset considerably. Owing to technical issues, drogue detection in the Southern Ocean was less reliable during the 2007-2008 period investigated in this study, as many of the drifting buoys in the area did not have tether-strain gauges 
(a)

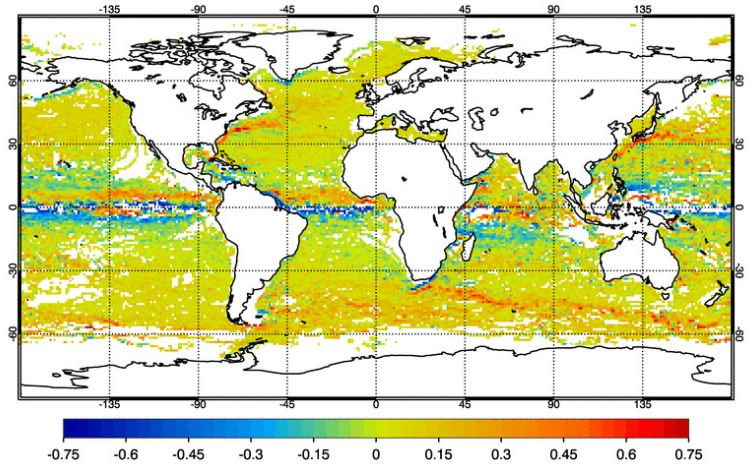

(b)

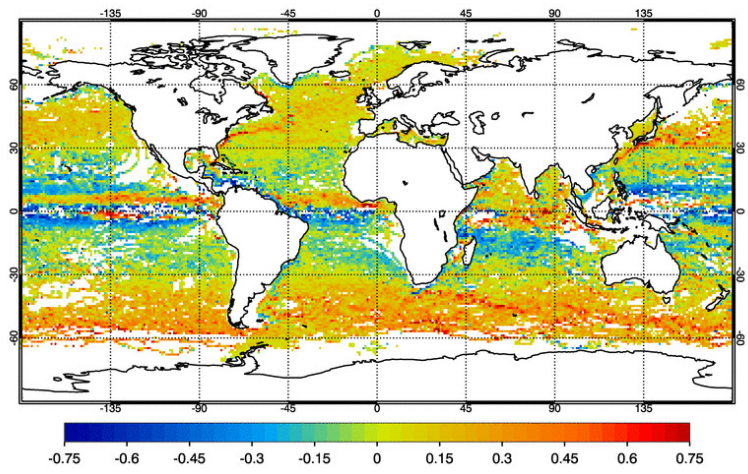

(c)

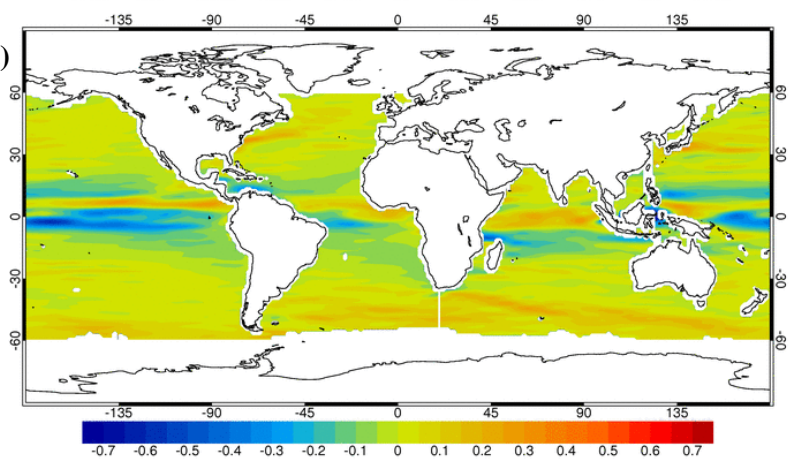

Fig. 5. Average zonal velocity fields over the 2007-2008 study period in $1^{\circ}$ bins: (a) FOAM model values and (b) drifter-derived observation values at observation points. The corresponding averaged OSCAR zonal velocity is shown in (c).

to monitor drogue presence - relying instead on the less efficient submergence sensor method. Also manufacturing problems may have affected some of the drogue lifetimes during this period (R. Lumpkin, personal communication, 2010). Moreover, waves in the Southern Ocean can be significantly higher than in other areas of the ocean which could prevent the older submergence sensors from correctly diagnosing drogue detachment owing to continued regular submergence by waves.

Recent findings of Grodsky et al. (2011) highlight the fact that drogue loss in the global array is an issue, reporting that approximately $30 \%$ of buoys lose their drogues within 3 months of release and roughly $90 \%$ of drogues are lost within 18 months. They estimate the fraction of unidentified undrogued buoys in the global array and report it to be consistently above $67 \%$ for most of the study period 2007-2008 and as high as $80 \%$ for parts of 2007 . Evidence suggests that the switch to tether-strain gauge from submergence sensor method has greatly increased the probability of successful drogue loss detection. Grodsky et al. (2011) show that the number of unidentified undrogued drifters in the array has steadily decreased since its maximum in 2007 and that by the end of 2009 things have improved considerably (see their Fig. 3d).

Grodsky et al. (2011) further suggest that, during the problematic period 2004-2008, drifters less than 90 days old should be used as a proxy for drifters with drogues still attached, i.e. all buoys older than 90 days should be discarded. A further analysis was performed comparing the FOAM currents with a subset of the pseudo-Eulerian currents derived from buoys no older than 90 days. However, the corresponding summary statistics (not shown here) were not very different from those in Table 2. Imposing a 90-day age limit removed approximately $82 \%$ of the Southern Ocean drifters, so the number of resulting co-locations is most likely too small to generate useful statistics for our relatively short analysis period. Moreover, with $30 \%$ of buoys losing their drogues on average within the first 90 days of operation, it is probable that a number of these buoys do not have drogues. This figure of $30 \%$ is based on the average number of buoys that lose their drogues, so this may be more than $30 \%$ in the Southern Ocean where the vertical shear on the drogue tethers is likely to be a lot higher, on account of the increased wind and wave effects.

In summary, the drifter-derived velocities in the Southern Ocean show a significant difference from the modelled FOAM currents. This difference could be owing to a bias in the drifter current dataset, the most likely cause of which is slippage of drifters in the high Southern Ocean winds. This is further supported by the diminished frontal structure in the ACC observations suggesting that the drifters are, to a certain extent, following the zonal winds rather than the bathymetrically confined ACC jets. Wind-slip caused by unidentified drogue loss is also likely to contribute towards this bias with 2007-2008 being part of the worst affected period according to the findings of Grodsky et al. (2011). Falco and Zambianchi (2011), under the framework of the World Ocean Circulation Experiment (WOCE), use SVP drifters to investigate the near-surface structure of the ACC for the period 1989-2002 - a period when unidentified drogue loss was not thought to be a problem. Their findings appear not to have this bias, which implies that unidentified undrogued drifters are more likely to be the cause of the observed differences than the windage estimate of $0.1 \%$ being invalid in this region of very high winds. 


\section{Impact of assimilation and the V1 upgrade on FOAM currents}

In this section, we explore the impact that the data assimilation scheme and the recent FOAM V1 upgrade have on the quality of the FOAM currents. We do this by assessing two additional hindcast experiments for the period 2007-2008: one using the FOAM V1 system but without data assimilation; and the other using the fully assimilative FOAM V0 system. The velocity fields from these hindcast integrations were analysed in the same manner as detailed above, and summary statistics were compared to those obtained in Sect. 5. These comparisons can be found in Fig. 6, which shows Taylor plots of zonal and meridional velocities (Fig. 6a and $b$ respectively) from the FOAM V1 hindcast (circles), the FOAM V1 non-assimilative hindcast (crosses) and the FOAM V0 hindcast (squares) for a subset of the assessment regions considered - namely the global ocean (black), North Atlantic (red), tropical Pacific (green) and Southern Ocean (blue).

\subsection{Impact of data assimilation}

Data assimilation in the FOAM system is performed using observations of sea surface temperature (SST), sea level anomaly (SLA), sea-ice concentration and profiles of temperature and salinity. Although velocities are not explicitly assimilated, the SLA and profile assimilation do have a direct effect on the current fields through the implementation of velocity balancing increments (see Martin et al., 2007 for more details). Moreover, the changes made to the sea surface height fields, and the modified density gradients associated with the profile assimilation, will also have an effect on the modelled currents. Therefore, the comparisons made in this section will demonstrate the impact that assimilating these other quantities has on the quality of the FOAM surface currents.

From Fig. 6 it is clear that the impact of data assimilation is positive. In all cases, the velocities from the full FOAM hindcast experiment (circles) have much higher correlations and lower RMS values than the corresponding values for the non-assimilative hindcast (crosses). This is particularly true for the meridional currents in the tropical Pacific, for which the assimilation increases the correlation considerably from approximately 0.3 to over 0.55 . Additionally, the assimilation generally has a positive effect on the variability of the FOAM system currents for both zonal and meridional flows. This is more noticeable in "dynamic" regions with high mesoscale activity such as the Gulf Stream in the North Atlantic. This can be seen in Fig. 6 by comparing the red circles with the red crosses. Interestingly, the zonal currents in the Pacific Ocean, in particular the tropical Pacific, are less variable in the assimilative experiment than the free running one. (a)

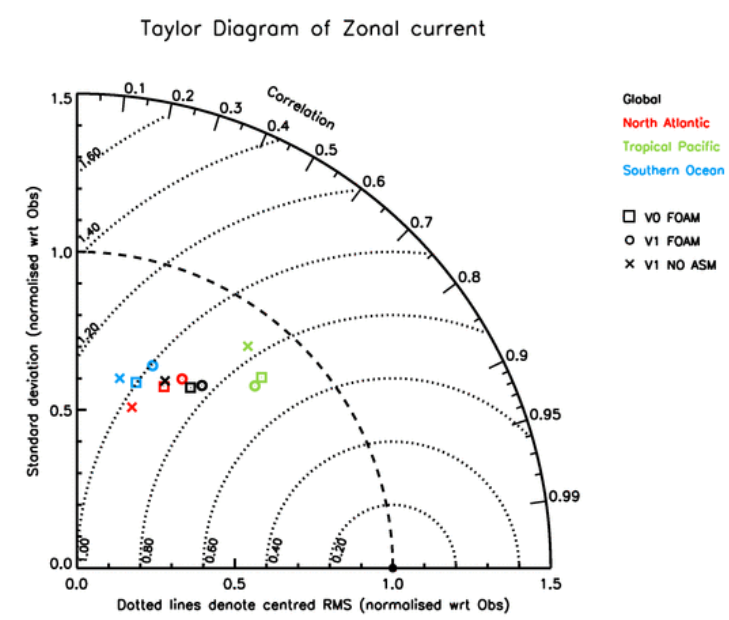

(b)

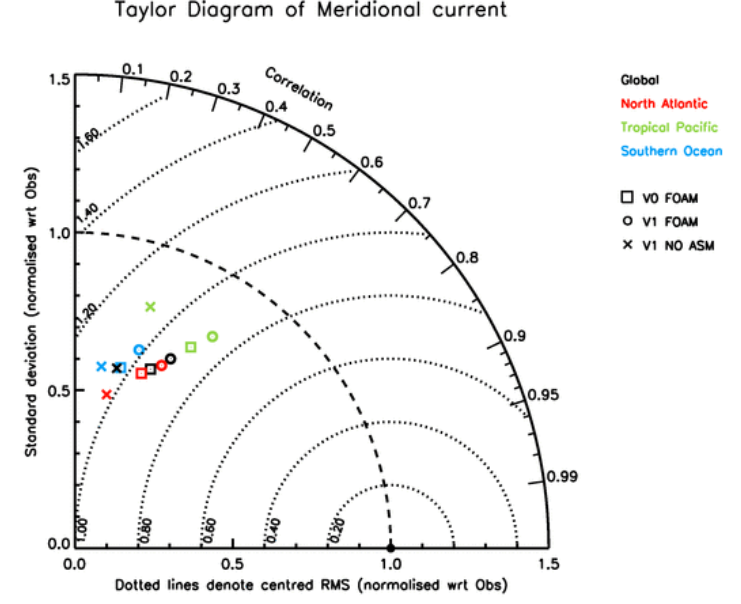

Fig. 6. Taylor plots of the global drifter current validation to show the benefit of running with data assimilation and the impact of the FOAM V1 changes for (a) zonal current and (b) meridional current. Each plot contains comparisons between the FOAM V1 hindcast run (circles), the FOAM V1 non-assimilative hindcast run (crosses) and the FOAM V0 hindcast run (squares), each for a subset of the regions presented in Table 2 - namely Global (black), North Atlantic (red), tropical Pacific (green) and Southern Ocean (blue).

\subsection{Impact of the FOAM V1 upgrade}

A number of changes were made to the FOAM system as part of the V1 upgrade as was briefly outlined in Sect. 2. Of these modifications, the changes to the data assimilation would be expected to make the most difference to the modelled surface currents. In particular, the implementation of newly calculated, seasonally varying, error covariance estimates, along with an increase in the number of available SLA observations, will lead to differences in the currents most significantly at the mesoscale. Additionally, the use of a different mean dynamic topography (MDT) for the SLA assimilation would be expected to have an effect on the large-scale 
circulation of the model and lead to differences in the longterm time-mean flows (Haines et al., 2011).

The effects of the FOAM V1 upgrade on the modelled surface currents can be seen in the Taylor plots in Fig. 6 for a subset of the assessment regions. Comparing the statistics for the V1 (circles) and V0 (squares) hindcast integrations shows the impact of the V1 upgrade to be positive. In all of the regions considered, and in particular the global ocean as a whole, the FOAM V1 currents were better correlated to the observations than the V0 currents with lower RMS errors. Moreover, the normalised standard deviations were generally higher for the V1 velocities in particular for the meridional currents. These improvements to the surface current statistics suggest that the assimilation changes made as part of the V1 upgrade have better constrained the system. In particular, the updated error covariances mean that the data assimilation scheme appears to be fitting the SLA data a lot more closely at V1 than at V0 (D. Lea, personal communication, 2011). Interestingly, the impact of the V1 upgrade in the tropical Pacific is a reduction in the zonal velocity variability, much as was true for the impact of data assimilation.

We have shown that both the data assimilation system and the V1 upgrade improve the FOAM surface current forecasts. Although this improvement generally applies to all of the assessment regions, there appears to be a negative impact to the variability of the zonal currents in the tropical Pacific, which will require further investigation. Further details of the temperature and salinity biases in the FOAM model (obtained by comparing the time-averaged assimilation increments) and the differences between the V0 and V1 systems can be found in Storkey (2011).

\section{Summary}

Knowledge of ocean currents is important for many marine applications, and there is an increasing need to validate the current predictions made by operational ocean forecasting systems such as FOAM. However, relative to quantities such as sea surface temperature, there are very few current observations in the public domain against which to perform this validation. Noticeable exceptions are the velocity measurements made by some of the moorings in the global tropical moored buoy array, but these are limited to the tropics. Of these moorings, many of the RAMA buoys in the Indian Ocean are presently providing velocity observations at a range of depths with data available via the TAO Project Office of NOAA/PMEL. The same is true, in part, for the PIRATA (Atlantic Ocean) and TAO/TRITON (Pacific Ocean) moorings, although only about half of all these moorings are equipped with current meters at present. This is a considerable improvement compared to the beginning of this century when currents were only available from a handful of tropical moorings.
Compared to the global tropical moored buoy array, the SVP drifter coverage is very good. There are some issues with the distribution of drifters though, with some areas being sampled a lot more regularly than others; in particular, there are very few drifting buoys in the Mediterranean Sea. Additionally, there are questions surrounding the drifter dataset with respect to the retention of the drogues, although recent issues relating to a lack of drogue loss detection appear to have been solved by the move to a generic tether-strain gauge. However, there still seems to be a drogue loss problem with an estimated $30 \%$ of drifters losing their drogues within the first 3 months after release. Finally, the severity of wind-slip in high winds (i.e. exceeding $10 \mathrm{~m} \mathrm{~s}^{-1}$ ) is not yet completely understood - mainly because it has proven too dangerous to carry out adequate tests in these conditions. It would prove useful to find out how much the SVP drifters are affected by the high winds and large waves of the Southern Ocean.

In this paper, we have described a simple method for inferring near-surface ocean velocities from GTS drifter positions in near-real time. We have demonstrated that these drifter-derived currents compare favourably with velocity observations measured by the global tropical moored buoy array. However, as discussed in Sect. 3, the pseudo-Eulerian currents are determined from Lagrangian drifter positions using a somewhat simplistic averaging scheme, which may have introduced some minor errors. In particular, the subsampling of the drifter positions and the decision to retain drifter reports, spanning a minimum of only $8 \mathrm{~h}$ per day, may be aliasing higher frequency motions such as tidal and inertial currents into the inferred velocity data. Although we expect that these issues will make a minimal difference to the results, future drifter-velocity assessments will compare the derived currents with the GDP quality-controlled velocities including results from a recent drogue presence re-evaluation (Lumpkin et al., 2012).

These pseudo-Eulerian drifter-derived currents have been used to evaluate the accuracy of modelled daily-mean currents from the Met Office's FOAM system. Results were consistently better for zonal current than for meridional current and generally better in the tropics and the North Pacific with some correlations exceeding 0.6 (a value widely taken as the lower bound for a useful forecast). In all regions, save for the Southern Ocean, the model is shown to be more skilful than the climatology, which is particularly true for meridional velocity. This suggests that the model has some skill at reproducing circulation features that the climatology is not able to capture such as small-scale features (e.g. mesoscale eddies, tropical instability waves) and circulations associated with inter-annual processes (e.g. ENSO). The Southern Ocean is an area for concern with very low correlations and a significant difference between the modelled currents and the drifter observations. However, we suspect that this bias is primarily caused by issues with the drifter-derived currents rather than the modelled currents. In particular, there is a suggestion that 
wind-slip in the Southern Ocean is impacting upon the quality of the pseudo-Eulerian drifter current estimates, which will require further investigation.

We have also used the drifter current technique to investigate the impact that the data assimilation scheme has on the quality of the FOAM currents. This method is ideally suited to this assessment, because independent current observations with global coverage are scarce, and these nearindependent data have not been assimilated by the system. We found that the data assimilation has a positive effect on the currents showing considerable improvements to correlation coefficients and RMS errors across the globe. Furthermore, the variability of the modelled currents benefited greatly from the assimilation, most noticeably in strongly eddying areas such as the Gulf Stream. We also showed how this method has been used at the Met Office to independently assess the surface currents for potential system upgrades and showed that the latest version of FOAM (termed V1) out-performs the previous V0 implementation of FOAM described in Storkey et al. (2010).

Future FOAM velocity assessments will analyse the next implementation of FOAM, due for operational implementation in autumn 2012, and will focus on the later period 2010-2011 when drogue detection had improved. The next FOAM system will, amongst other improvements, include a higher vertical resolution 75 level ocean model coupled to the Los Alamos CICE ice model (Hunke and Lipscomb, 2008). It will also use hourly, rather than 6-hourly, wind fields for the surface boundary conditions and will use a new variational data assimilation scheme NEMOVAR (Mogensen et al., 2009). In addition to these drifter-velocity comparisons, further assessments are planned using the velocities observed by the global tropical moored buoy array. This will involve experimenting with some more flexible neighbourhood verification techniques (Ebert, 2009; Gilleland et al., 2009) and investigation into site-specific skill of the FOAM currents. There are also plans to explore the use of synthetic aperture radar (SAR) and HF Radar observations for the purpose of validating FOAM velocity fields.

\section{Copyright statement}

This work is distributed under the Creative Commons Attribution 3.0 License together with an author copyright. This license does not conflict with the regulations of the Crown Copyright.

Acknowledgements. Funding support from the UK Ministry of Defence and the European Community's Seventh Framework Programme FP7/2007-2013 under grant agreement no. 218812 (MyOcean) is gratefully acknowledged. The data used for this study were obtained from numerous sources all of which are gratefully acknowledged by the authors. The drifter data were obtained via the Global Telecommunication System
(GTS). Drifter status and drogue information along with the drifter velocity climatology were obtained from the Global Drifter Program (GDP) http://www.aoml.noaa.gov/phod/dac/. The global tropical moored buoy array velocity observations were obtained from the TAO project office of NOAA/PMEL http://www.pmel.noaa.gov/tao/data_deliv/deliv.html. The OSCAR surface current data were obtained from the OSCAR website http://www.oscar.noaa.gov/. The authors are also grateful for the help and advice received from many others working within ocean forecasting research and development at the Met Office in particular Dave Storkey, Daniel Lea, John Siddorn, Catherine Guiavarc'h and Andrew Ryan. Additionally, Ed Blockley would like to thank Rick Lumpkin (NOAA/AOML) and Bernard Barnier for some very useful discussions as well as Alistair Sellar and Mike Bell (Met Office) for their helpful comments and useful ideas regarding the structure of the paper. The authors would like to further thank Rick Lumpkin and another anonymous reviewer for several constructive comments which have helped to improve this manuscript.

Edited by: J. A. Johannessen

\section{References}

Bonjean, F. and Lagerloef, G. S. E.: Diagnostic model and analysis of the surface currents in the tropical Pacific Ocean, J. Phys. Oceanogr., 32, 2938-2954, 2002

Brushett, B. A., King, B. A., and Lemckert, C. J.: Evaluation of met-ocean forecast data effectiveness for tracking drifters deployed during operational oil spill response in Australian waters, J. Coastal Res., 64, 991-994, 2011

Burchard, H.: Energy-conserving discretisation of turbulent shear and buoyancy production, Ocean Model., 4, 347-361, 2002.

Cunningham, S. A., Alderson, S. G., King, B. A., and Brandon, M. A.: Transport and variability of the Antarctic Circumpolar Current in Drake Passage, J. Geophys. Res., 108, 8084, doi:10.1029/2001JC001147, 2003.

Davidson, F. J. M., Allen, A., Brassington, G. B., Breivik, Ø., Daniel, P., Kamachi, M., Sato, S., King, B., Lefevre, F., Sutton, M., and Kaneko, H.: Applications of GODAE ocean current forecasts to search and rescue and ship routing, Oceanography, GODAE Special issue feature, 22, 176-181, 2009.

Deng, Z., Xie, L., Liu, B., Wu, K., Zhao, D., and Yu, T.: Coupling winds to ocean surface currents over the global ocean, Ocean Model., 29, 261-268, 2009.

Dohan, K. and Maximenko, N.: Monitoring ocean currents with satellite sensors, Oceanography, 23, 94-103, 2010.

Dombrowsky, E., Bertino, L., Brassington, G. B., Chassignet, E. P., Davidson, F., Hurlburt, H. E., Kamachi, M., Lee, T., Martin, M. J., Mei, S., and Tonani, M.: GODAE systems in operation, Oceanography, GODAE Special issue feature, 22, 80-95, 2009.

Drévillon, M., Bourdallé-Badie, R., Derval, C., Drillet, Y., Lellouche, J. M., Rémy, E., Tranchant, B., Benkiran, M., Greiner, E., Guinehut, S., Verbrugge, N., Garric, G., Testut, C. E., Laborie, M., Nouel, L., Bahurel, P., Bricaud, C., Crosnier, L., Dombrowsky, E., Durand, E., Ferry, N., Hernandez, F., Le Galloudec, O., Messal, F., and Parent, L.: The GODAE/MercatorOcéan global ocean forecasting system: results, applications and prospects, J. Oper. Ocean, 1, 51-57, 2008. 
Ebert, E. E.: Neighborhood verification: A strategy for rewarding close forecasts, Weather Forecast., 24, 1498-1510, 2009.

Eden, C. and Dietze, H.: Effects of mesoscale eddy/wind interactions on biological new production and eddy kinetic energy, J. Geophys. Res.-Oceans, 114, C05023, doi:10.1029/2008JC005129, 2009.

Falco, P. and Zambianchi, E.: Near-surface structure of the Antarctic Circumpolar Current derived from World Ocean Circulation Experiment drifter data, J. Geophys. Res., 116, C05003, doi:10.1029/2010JC006349, 2011.

Gilleland, E., Ahijevych, D., Brown, B. G., Casati, B., and Ebert, E. E.: Intercomparison of spatial forecast verification methods, Weather Forecast., 24, 1416-1430, 2009.

Grodsky, S. A., Lumpkin, R., and Carton, J. A.: Spurious trends in global surface drifter currents, Geophys. Res. Lett., 38, L10606, doi:10.1029/2011GL047393, 2011.

Haines, K., Johannessen, J. A., Knudsen, P., Lea, D., Rio, M.-H., Bertino, L., Davidson, F., and Hernandez, F.: An ocean modelling and assimilation guide to using GOCE geoid products, Ocean Sci., 7, 151-164, doi:10.5194/os-7-151-2011, 2011.

Hayes, S. P., Mangum, L. J., PiCaut, J., Sumi, A., and Takeuchi, K.: TOGA-TAO: A moored array for real-time measurements in the Tropical Pacific Ocean, B. Am. Meteorol. Soc., 72, 339-347, 1991.

Hernandez, F., Bertino, L., Brassington, G. B., Chassignet, E., Cummings, J., Davidson, F., Drevillon, M., Garric, G., Kamachi, M., Lellouche, J.-M., Mahdon, R., Martin, M. J., Ratsimandresy, A., and Regnier, C.: Validation and intercomparison studies within GODAE, Oceanography, GODAE Special issue feature, 22, 128$143,2009$.

Hollingsworth, A., Arpe, K., Tiedtke, M., Capaldo, M., and Savijärvi, H.: The performance of a medium-range forecast model in winter - impact of physical parameterizations, Mon. Weather. Rev., 108, 1736-1773, 1980.

Huckerby, J.: Marine energy: resources, technologies, research and policies, in Operational Oceanography in the 21st Century, Springer, Brassington and Schiller, 2011.

Hunke, E. C. and Lipscomb, W. H.: CICE: the Los Alamos sea ice model. Documentation and software users manual, Version 4.0, Fluid Dynamics Group, Los Alamos National Laboratory, Los Alamos, 2008.

Hyder, P., Storkey, D., Blockley, E. W., Guiavarc'h, C., Siddorn, J. R., Martin, M. J., and Lea, D.: Assessing equatorial surface currents in the FOAM Global and Indian Ocean models against observations, including the global tropical moored buoy array, J. Operational Oceanography, in press, 2011.

Ingleby, N. B. and Lorenc, A. C.: Bayesian quality control using multivariate normal distributions, Q. J. Roy. Meteor. Soc., 119, 1195-122, 1993.

Jacobs, G. A., Woodham, R., Jourdan, D., and Braithwaite, J.: GODAE applications useful to navies throughout the world, Oceanography, 22, 182-189, 2009.

King, B., Brushett, B., Gilbert, T., and Lemckert, C.: Applications for metocean forecast data - maritime transport, safety and pollution, in Operational Oceanography in the 21st Century, Springer, Brassington and Schiller, 2011.

Larnicol, G., Guinehut, S., Rio, M.-H., Drevillon, M., Faugere, Y., and Nicolas, G.: The global observed ocean products of the French Mercator project, in: Proceedings of the Symposium on
15 Years of Progress in Radar Altimetry, Venice, Italy, 13-18 March 2006, European Space Agency Special Publication SP614, 2006.

Lumpkin, R. and Garraffo, Z.: Evaluating the decomposition of Tropical Atlantic drifter observations, J. Atmos. Ocean. Tech., 22, 1403-1415, 2005

Lumpkin, R. and Garzoli, S. L.: Near-surface circulation in the Tropical Atlantic Ocean, Deep-Sea Res. Pt. I, 52, 495-518, 2005.

Lumpkin, R. and Pazos, M.: Measuring surface currents with Surface Velocity Program drifters: the instrument, its data, and some recent results, in: Lagrangian Analysis and Prediction of Coastal and Ocean Dynamics (LAPCOD), edited by: Griffa, A., Kirwan, A. D., Mariano, A. J., Özgökmen, T., and Rossby, T., Cambridge University Press, chapter 2, 39-67, 2007.

Lumpkin, R., Grodsky, S. A., Centurioni, L., Rio, M.-H., Carton, J. A., and Lee, D.: Removing spurious low-frequency variability in drifter velocities, J. Atmos. Ocean. Technol., in review, 2012.

Madec, G.: NEMO ocean engine, Note du Pole de modélisation, Institut Pierre-Simon Laplace (IPSL), France, 27, 1288-1619, 2008.

Martin, M. J.: Ocean forecasting systems: product evaluation and skill, in: Operational Oceanography in the 21st Century, Springer, Brassington and Schiller, 2011.

Martin, M. J., Hines, A., and Bell, M. J.: Data assimilation in the FOAM operational short-range ocean forecasting system: a description of the scheme and its impact, Q. J. Roy. Meteor. Soc. 133, 59-89, 2007.

Maximenko, N. and Hafner, J.: SCUD: Surface CUrrents from Diagnostic model, IPRC Technical Note No. 5, 16 February 2010, 17 pp., 2010.

Maximenko, N., Niiler, P., Centurioni, L., Rio, M.-H., Melnichenko, O., Chambers, D., Zlotnicki, V., and Galperin, B.: Mean Dynamic Topography of the ocean derived from satellite and drifting buoy data using three different techniques, J. Atmos. Ocean. Tech., 26, 1910-1919, 2009.

McPhaden, M. J., Meyers, G., Ando, K., Masumoto, Y., Murty, V. S. N., Ravichandran, M., Syamsudin, F., Vialard, J., Yu, L., and Yu, W.: RAMA: The Research Moored Array for African-AsianAustralian Monsoon Analysis and Prediction, B. Am. Meteorol. Soc., 90, 459-480, 2009.

Mogensen, K. S., Balmaseda, M. A., Weaver, A., Martin, M. J., and Vidard, A.: NEMOVAR: A variational data assimilation system for the NEMO ocean model, ECMWF newsletter, 2009.

Murphy, A. H. and Epstein, E. S.: Skill scores and correlation coefficients in model verification, Mon. Weather Rev., 117, 572-581, 1989.

Niiler P., Sybrandy, A. S., Bi, K., Poulain, P.-M., and Bitterman, D.: Measurements of the water-following capability of holeysock and TRISTAR drifters, Deep-Sea Res. Pt. I, 42, 1951-1955, 1957-1964, 1995.

Olbers, D., Borowski, D., Völker, C., and Wölff, J.-O.: The dynamical balance, transport and circulation of the Antarctic Circumpolar Current, Antarct. Sci., 16, 439-470, 2004.

Orsi, A. H., Whitworth III., T., and Nowlin Jr., W. D.: On the meridional extent and fronts of the Antarctic Circumpolar Current, Deep-Sea Res. Pt. I, 42, 641-673, 1995.

Poulain, P.-M., Gerin, R., Mauri, E., and Pennel, R.: Wind Effects on drogued and undrogued drifters in the eastern Mediterranean, J. Atmos. Ocean. Tech., 26, 1144-1156, 2009. 
Rio, M.-H., Schaeffer, P., Hernandez, F., and Lemoine, J.-M.: The estimation of the ocean Mean Dynamic Topography through the combination of altimetric data, in-situ measurements and GRACE geoid: from global to regional studies, Proceedings of the GOCINA international workshop, Luxembourg, 2007.

Rio, M.-H., Guinehut, S., and Larnicol, G.: New CNES-CLS09 global mean dynamic topography computed from the combination of GRACE data, altimetry, and in situ measurements, J. Geophys. Res., 116, C07018, doi:10.1029/2010JC006505, 2011.

Roberts, C. M.: Connectivity and management of Caribbean coral reefs, Science, 278, 1454-1457, 1997.

Servain, J., Busalacchi, A. J., McPhaden, M. J., Moura, A. D., Reverdin, G., Vianna, M., and Zebiak, S. E.: A pilot research moored array in the Tropical Atlantic (PIRATA), B. Am. Meteorol. Soc., 79, 2019-2032, 1998.

Sokolov, S. and Rintoul S. R.: Circumpolar structure and distribution of the Antarctic Circumpolar Current fronts: 1, Mean circumpolar paths, J. Geophys. Res., 114, C11018, doi:10.1029/2008JC0051082009.
Storkey, D.: Summary of large-scale biases in the global FOAM ocean forecasting system, Met Office Forecasting Research Technical Report, 554, 2011.

Storkey, D., Blockley, E. W., Furner, R., Guiavarc'h, C., Lea, D., Martin, M. J., Barciela, R. M., Hines, A., Hyder, P., and Siddorn, J. R.: Forecasting the ocean state using NEMO: The new FOAM system, J. Oper. Oceanogr., 3, 3-15, 2010.

Sudre, J. and Morrow, R.: Global surface currents: a high-resolution product for investigating ocean dynamics, Ocean Dynam., 58, 101-118, 2008.

Taylor, K. E.: Summarizing multiple aspects of model performance in a single diagram, J. Geophys. Res., 106, 7183-7192, 2001.

Timmermann R., Goosse, H., Madec, G., Fichefet, T., Ethe, C., and Duliere, V.: On the representation of high latitude processes in the ORCA-LIM global coupled sea ice-ocean model, Ocean Model., 8, 175-201, 2005.

Whitworth III., T. and Peterson, R. G.: Volume transport of the Antarctic Circumpolar Current from bottom pressure measurements, J. Phys. Oceanogr., 15, 810-816, 1995. 